\title{
Diagnostic tests of placenta accreta index score (PAIS) as supporting prenatal diagnosis and outcomes of maternal neonatal in abnormally invasive placenta management at general hospital of Hasan Sadikin Bandung
}

\author{
Sefty Mariany Samosir*, Setyorini Irianti, Dian Tjahyadi
}

Department of Obstetrics and Gynecology, Faculty of Medicine, Padjajaran University, Bandung, Indonesia

Received: 17 July 2017

Accepted: 29 July 2017

\section{*Correspondence:}

Dr. Sefty Mariany Samosir,

E-mail: seftymariany@yahoo.com

Copyright: () the author(s), publisher and licensee Medip Academy. This is an open-access article distributed under the terms of the Creative Commons Attribution Non-Commercial License, which permits unrestricted non-commercial use, distribution, and reproduction in any medium, provided the original work is properly cited.

\section{ABSTRACT}

Background: The incidence of abnormally invasive placenta increases tenfold as the number of caesarian section increases in the past 50 years. Placenta previa accreta is strongly associated with massive bleeding and leads to maternal death. Prenatal diagnosis helps in planning the delivery to reduce the risk of bleeding and possible complications. This study aims to find out diagnostic value of Placenta Accreta Index Score (PAIS) as supporting tool in prenatal diagnostic of abnormally invasive placenta.

Methods: The diagnostic test was undertaken in May 2017 at General Hospital of Hasan Sadikin, identifying patients with placenta previa with history of caesarian section between May 2016-May 2017. PAIS were obtained and compared with histopathological findings.

Results: Among 21 placenta previa patients with post caesarian section, $10(47.6 \%)$ of them histopathologically proven as abnormally invasive placenta. With statistical analysis accuracy values obtained PAIS and histopathological findings in patient with placenta previa is 0.762 (good). Diagnostic value of PAIS with histopathological findings in placenta previa patient had a sensitivity $70 \%$, a specificity $81,8 \%$, positive predictive value (PPV) $77.8 \%$, and negative predictive value (NPV) $75 \%$ by PAIS cut off point is 3.125 . No maternal death. Mean duration of postoperative care was 5 days. Average total bleeding during surgery is $2622 \mathrm{ml}$ with lowest postoperative hemoglobin $8.36 \mathrm{~g} / \mathrm{dl}$. All babies born with appropriate to gestational birth weight with average first minute APGAR was 7 and without fetal anemia.

Conclusions: PAIS can be used to help to predict the risk of abnormally.

Keywords: Abnormally invasive placenta, Accreta index, Prenatal diagnostic

\section{INTRODUCTION}

Placenta previa is a placenta that inserts in the lower segment of the uterus so it cover or approach to the ostium uteri internum, whereas in normal conditions the placenta inserts on the upper segment of the uterus. ${ }^{1}$ Placenta accreta is also known as abnormally morbid adherence of the placenta or abnormally invasive placenta (AIP), a common terminology for the condition of placenta whose corral villi perform a deeper invasion than it should be. Histopathologically, based on the depth of invasion of the corral villi, it is divided into placenta accreta, increta, and perretra. ${ }^{2}$ 
The incidence of abnormalities of rare placental invasions has risen to tenfold with increasing numbers of cesarean section in the last 50 years. ${ }^{3}$ In the period 1982 - 2002 the incidence rate of placental invasion was 1: 533 labor, increasing significantly compared to the reports in 1970 1980 ranged from 1: 4027 to 1: 2510 labor. ${ }^{4}$ Former cesarean section is a risk factor for placenta previa and placenta accreta.The more the cesarean section was done previously will increase the risk of placenta previa and placenta accreta. ${ }^{5}$

Placenta previa, accompanied by accreta is closely related to massive obstetric hemorrhage, it can lead to serious pregnancy complications, and potentially lead to maternal death. ${ }^{1,6}$ Placenta accreta is also common cause of peripartum emergency hysterectomy, which ranges from $51.1 \% .^{7,8}$ The placenta accreta is reported to cause $60 \%$ maternal morbidity and $7 \%$ mortality.Complications for perinatal also increase mainly due to preterm labor and birth with a small gestasional age. , $^{10}$

The diagnosis of abnormally invasive placenta when prenatal is the most important thing that will affect the outcome.Prenatal diagnosis will provide an opportunity for proper planning of labor so that it can predict the possibility of bleeding and complications that might be occur.In addition, knowing placenta accreta during prenatal will allow for the elective preparation of the multidisciplinary surgical team. ${ }^{11}$

Considering the importance of diagnosis of abnormally invasive placenta in prenatal, the researcher intends to conduct diagnostic test against placental index score of accreta recommended by American Journal of Obstetrics and Gynecology (AJOG) in 2014 and compared with histopathology result as gold standard of AIP.

\section{METHODS}

This research is a descriptive research in the form of diagnostic test design. The study was conducted in May 2017 at general hospital of Hasan Sadikin Bandung which is a level III hospital in Indonesia. The selected sample was patients with placenta previa who had a history of caesarean section in the period May 2016 May 2017 at the RSUP. Dr. Hasan Sadikin Bandung. The sample was divided into two groups: the first group was placental invasion group and the second was not placental invasion.

The maternal and neonatal outcomes in the treatment of AIP proven cases histopathologically will be presented descriptively in terms of average, lowest and highest scores, and percentages.

Capability index score of placenta accreta AJOG recommendation to predict AIP using Receiver Operating Characteristic curve (ROC) with the output of Area Under the Curve (AUC) and the cut-off point. Furthermore, the sensitivity and 1-specificity tables are also made so the best cut-off point can be determined. The next analysis uses $2 \times 2$ tables with outputs in the form of sensitivity, specificity, positive predictive value, negative predictive value, and accuracy.

\section{RESULTS}

In the period May 2016 - May 2017, at the general hospital of Hasan Sadikin Bandung has 21 gravida with a history of cesarean section with placenta previa. From 21 gravida, $10(47.6 \%)$ were shown histopathologically as abnormally invasive placenta.

Table 1: Demographic characteristics based on histopathologic findings of placental invasion.

\begin{tabular}{|llll|}
\hline Characteristic & $\begin{array}{l}\text { Placental } \\
\text { invasion } \\
(\mathrm{n}=10)\end{array}$ & $\begin{array}{l}\text { Non placental } \\
\text { invasion } \\
(\mathrm{n}=11)\end{array}$ & $\mathrm{P}$ \\
\hline Age & 33.6 & 33.09 & 0.642 \\
\hline $\begin{array}{l}\text { Gestational } \\
\text { Age }\end{array}$ & 34.2 & 33.82 & 0.474 \\
\hline Seksio sesarea history $\mathrm{n}(\%)$ & & 1.000 \\
\hline 1 & $7(70)$ & $7(63.6)$ & \\
\hline 2 & $3(30)$ & $4(36.4)$ & \\
\hline$\geq 3$ & 0 & 0 & 0.926 \\
\hline Curettage history, $\mathrm{n}(\%)$ & & \\
\hline 1 & $2(20)$ & $3(27.3)$ & \\
\hline$\geq 2$ & $1(10)$ & $1(9.1)$ & \\
\hline
\end{tabular}

Table 1 shows that there is no difference between groups of placental invasion and non-placental invasion based on age or gestational age when ultrasound examination is performed. The number of cesarean section and curettage also did not show any difference in the placental invasion group and the non-placental invasion.

Table 2: Parameters of ultrasound findings between placental invasion groups and non-placental invasion.

\begin{tabular}{|llll|}
\hline Parameter & $\begin{array}{l}\text { Placental } \\
\text { invasion } \\
(\mathrm{n}=10)\end{array}$ & $\begin{array}{l}\text { Non placental } \\
\text { invasion } \\
(\mathrm{n}=11)\end{array}$ & $\mathrm{P}$ \\
$\begin{array}{l}\text { Plasenta previa } \\
\text { anterior n }(\%)\end{array}$ & $10(100)$ & $3(27.3)$ & 0.001 \\
\hline Lacuna intraplacenta n (\%) & & 0.000 \\
\hline Grade 0 & $0(0)$ & $6(54.5)$ & \\
\hline Grade 1 & $0(0)$ & $4(36.4)$ & \\
\hline Grade 2 & $4(40)$ & $1(9.1)$ & 0.001 \\
\hline Grade 3 & $6(60)$ & $0(0)$ & 0.000 \\
\hline Bridging vessels & $7(70)$ & $0(0)$ & \\
\hline $\begin{array}{l}\text { Thickness of the } \\
\text { smallest placental } \\
\text { myometrium, mm }\end{array}$ & $\begin{array}{l}2.79 \\
{[0.0,4.5]}\end{array}$ & 4.91 & {$[3.5,5.5]$} \\
\hline
\end{tabular}

The ultrasonographic findings are presented in Table 2. Placenta previa that inserted on the anterior wall significantly indicates association with the risk of placental invasion. 
Ten histopathologically-proven gravida as abnormally invasive placenta, $100 \%$ is a placenta previa involving the anterior wall of the uterus, with a value of $\mathrm{p}<0.05$. Other ultrasound examination parameters, intra placental lacuna, bridging vessels and the smallest retroplacent myometrial thickness also yield $\mathrm{p}$ value $<0.05$.

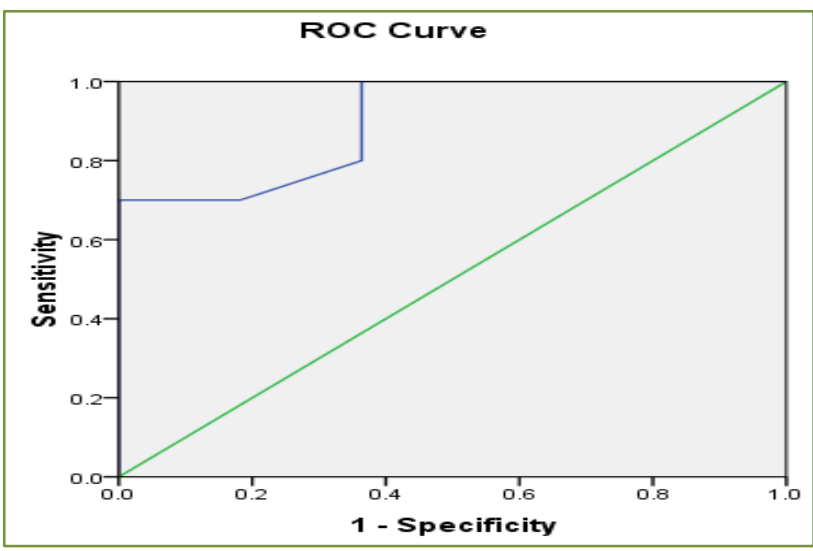

Figure 1: Analysis of receiver operating characteristic curve and under the curve area of placenta accreta index score.

The results of the analysis of the receiver operating characteristic curve (ROC) score of placenta accreta between the index and histopathological results can be seen in Figure 1.

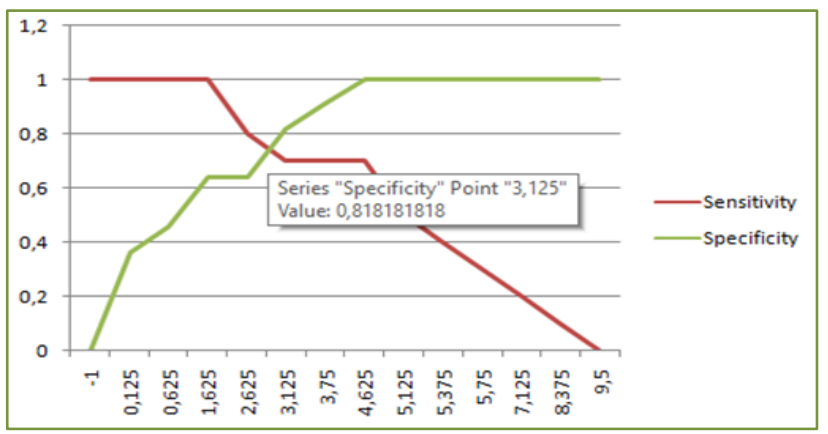

Figure 2: Cutt-off poin placental accreta index score.

Based on the results of the ROC curve analysis above, it was found that the under-the-curve area of the placenta accreta index score was 0.9 (95\% confidence interval 0.769-1.031).

In this research, the best cut-off point of placenta accreta index score is 3.125 according to the most optimal coordinate sensitivity and specificity on ROC curve. The results of the examination score of placenta accreta index based on the cut-off point to the value of 3.125 compared with the gold standard histopathological results can be seen in Table 3.

Based on the data in Table 3, the result of diagnostic test of placenta index score is $70 \%$ sensitivity, $81.8 \%$ specificity, $77.8 \%$ positive prediction, negative prediction
$75 \%$, and accuracy of 0.762 (good). An accurate prenatal diagnosis of ten cases of abnormally invasive placenta makes it possible to conduct a multidisciplinary preparatory work out, thus achieving good outcomes for maternal and neonatal care.

Table 3: Results of placental index score of accreta index compared to histopathology result.

\begin{tabular}{|c|c|c|c|c|}
\hline & \multicolumn{2}{|c|}{ Histopathology } & \multirow[t]{2}{*}{ Total } \\
\hline & & $\begin{array}{l}\text { Placental } \\
\text { invasion }\end{array}$ & $\begin{array}{l}\text { Non placental } \\
\text { invasion }\end{array}$ & \\
\hline \multirow{2}{*}{$\begin{array}{l}\text { Placental } \\
\text { accreta } \\
\text { index score }\end{array}$} & $\geq 3.125$ & 7 & 2 & 9 \\
\hline & $<3.125$ & 3 & 9 & 12 \\
\hline Total & & 10 & 11 & 21 \\
\hline
\end{tabular}

Table 4 shown the results of maternal and neonatal outcomes in AIP cases diagnosed at prenatal at general hospital Hasan Sadikin Bandung.

Table 4. Maternal and neonatal outcomes in abnormally invasive placenta cases prenatal $(n=10)$.

\begin{tabular}{|ll|}
\hline $\begin{array}{l}\text { Maternal } \\
\text { Estimated bleeding during surgery } \\
(\mathrm{ml})\end{array}$ & $\mathbf{n = 1 0}$ \\
\hline PRC tranfusion (ml) & $387.78(0-1220)$ \\
\hline FFP tranfusion (ml) & $68.89(0-420)$ \\
\hline $\begin{array}{l}\text { Lowest haemoglobin post operation } \\
\text { (gr/dl) }\end{array}$ & $8.36(5.8-9.1)$ \\
\hline Post opeartion care (day) & $5(3-11)$ \\
\hline Intensive Care Unit, $\mathrm{n}(\%)$ & $1(10)$ \\
\hline Vesika urinaria injury n (\%) & $1(10)$ \\
\hline Re-open surgery & 0 \\
\hline Re-admission & 0 \\
\hline Neonatal & $34-35$ \\
\hline Gestational age at delivery (weeks) & \multicolumn{1}{|c|}{ (we } \\
\hline Birth weight compared to gestational age $\mathrm{n}(\%)$ \\
\hline Small period of pregnancy & 0 \\
\hline According to period of pregnancy & 10 \\
\hline Large period of pregnancy & 0 \\
\hline Apgar first minute & $7(3-8)$ \\
\hline Fetal anemia & 0 \\
\hline Neonatal intensive care unit & $1(10)$ \\
\hline
\end{tabular}

Ten cases of abnormally invasive placentas were treated in general hospital Hasan Sadikin did not find any maternal deaths. One patient $(10 \%)$ was admitted to the high-care unit for three days, while the other 9 required only regular room maintenance.

The average number of bleeding during surgery was 2622 $\mathrm{ml}$ with the lowest postoperative hemoglobin averaging $8.36 \mathrm{gr} / \mathrm{dl}$. There are one in ten AIP patients injected with urinary vesica.

No patients had re-open surgery or re-admission after postoperative care. Gestational age at termination of the average pregnancy is 34-35 weeks. All cases were born with a body weight corresponding to gestation, without 
fetal anemia. APGAR score in the first minute average is 7. One baby is treated in the neonatal intensive care unit after 3 days of age.

\section{DISCUSSION}

In this study, there was no difference between the groups that proved invasive placenta with non-invasive placenta based on age or gestational age when the ultrasound examination was performed.

The number of cesarean section and curettage also did not show any difference in the placental invasion group and not the placental invasion. This is different from the results of Twickler's et al, study of which states the number of caesarean section significantly increases the risk of placental invasion. ${ }^{12-15}$

The risk of placenta previa accreta increases with the number of cesarean sections namely, $11 \%, 40 \%$, and $>60 \%$ in patients with cesarean once, twice, and more than three times. ${ }^{16-21}$ While the characteristics of patients with abnormally invasive placenta in RSUP General Hospital of Dr. Hasan Sadikin in the past year is $70 \%$ has a history of cesarean section once and the remaining $30 \%$ with a history of cesarean section twice. In this study, the best total score of placenta accreta index score was 3.125 with $70 \%$ sensitivity, $81.8 \%$ specificity, this explains that the ability of total score of placenta accreta index $\geq 3.125$ to detect placenta invasive occurrence by $70 \%$ while ability total score of the placenta accreta index $<3.125$ to detect a non-invasive placenta occurrence of $81.8 \%$. In this study, 10 cases of abnormally invasive placenta were treated in RSUP General Hospital of Dr. Hasan Sadikin did not find any maternal deaths. In addition, no patients experienced re-open surgery or re-admission after postoperative care. All cases were born with a body weight corresponding to gestation, without fetal anemia. APGAR first minute average is 7 . One baby is treated in the neonatal intensive care unit after 3 days of age. This means the maternal and neonatal outcomes in the treatment of abnormally invasive placenta cases in the RSUP. Dr. Hasan Sadikin Bandung by using placenta accreta index score as prenatal support of diagnosis is good.

\section{CONCLUSION}

The placenta accreta score of the AJOG index has a sensitivity of $70 \%$, specificity of $81.8 \%$, a positive predictive value of $77.8 \%$, a negative predictive value of $75 \%$, and an accuracy of 0.762 to diagnose abnormal invasive placenta prenatal.

Funding: No funding sources Conflict of interest: None declared

Ethical approval: The study was approved by the Institutional Ethics Committee

\section{REFERENCES}

1. Oyelese Y, Smulian JC. Placenta evia, placenta accreta, and vasa previa. Obstet Gynecol. 2006;107(4):927-41.

2. Chantraine F, Langhoff- Roos J. Abnormally Invasive Placenta-AIP. Awareness and pro- active management is necessary. Acta Obstet Gynecol Scand. 2013;92(4):369-71.

3. ACOG committee opinion. Placenta accreta. Int $\mathbf{J}$ Gynecol Obstet. 2002;77:77-8.

4. Wu S, Kocherginsky M, Hibbard JU. Abnormal placentation: twenty-year analysis. Am J Obstet Gynecol. 2005;192(5):1458-61.

5. Clark SL, Koonings PP, Phelan JP. Placenta previa/accreta and prior cesarean section. Obstet Gynecol. 1985;66(1):89-92.

6. Walker MG, Allen L, Windrim RC, Kachura J, Pollard L, Pantazi $S$ et al. Multidisciplinary management of invasive placenta previa. J Obstet Gynaecol Can. 2013;35(5):417-25.

7. Daskalakis G, Anastasakis E, Papantoniou N, Mesogitis S, Theodora M, Antsaklis A. Emergency obstetric hysterectomy. Acta Obstet Gynecol Scand. 2007;86(2):223-7.

8. Orbach A, Levy A, Wiznitzer A, Mazor M, Holcberg G, Sheiner E. Peripartum cesarean hysterectomy: critical analysis of risk factors and trends over the years. J Matern-Fetal Neonatal Med. 2011;24(3):480-4.

9. Sumigama S, Itakura A, Ota T, Okada M, Kotani T, Hayakawa $\mathrm{H}$, et al. Placenta previa increta/percreta in Japan: a retrospective study of ultrasound findings, management and clinical course. J Obstet Gynaecol Res. 2007;33(5):606-11.

10. Eller A, Porter T, Soisson P, Silver RM. Optimal management strategies for placenta accreta. BJOG. 2009;116(5):648-54.

11. Garmi G, Salim R. Epidemiology, etiology, diagnosis, and management of placenta accreta. Obstet Gynecol Int. 2012;2012.

12. Committee P. Society for Maternal-Fetal Medicine, Belfort MA. Placenta accreta Am J Obstet Gynecol. 2010;203(5):430-9.

13. ACOG Committee Opinion. Placenta accreta. Obstet Gynecol. 2012;120:207-11.

14. D'antonio F, Iacovella C, Bhide A. Prenatal identification of invasive placentation using ultrasound: systematic review and meta- analysis. Ultrasound Obstet Gynecol. 2013;42(5):509-17.

15. Finberg H, Williams J. Placenta accreta: prospective sonographic diagnosis in patients with placenta previa and prior cesarean section. J Ultrasound Med. 1992;11(7):333-43.

16. Twickler DM, Lucas MJ, Balis AB, Santos-Ramos $\mathrm{R}$, Martin L, Malone S et al. Color flow mapping for myometrial invasion in women with a prior cesarean delivery. J Matern Fetal Med. 2000;9(6):330-5. 
17. Comstock $\mathrm{CH}$. The antenatal diagnosis of placental attachment disorders. Curr Opin Obstet Gynecol. 2011;23(2):117-22.

18. Guy GP, Peisner DB, Timor-Tritsch IE. Ultrasonographic evaluation of uteroplacental blood flow patterns of abnormally located and adherent placentas. Am J Obstet Gynecol. 1990;163(3):723-7.

19. Chou M, Ho E, Lee Y. Prenatal diagnosis of placenta previa accreta by transabdominal color Doppler ultrasound. Ultrasound Obstet Gynecol. 2000;15(1):28-35.

20. Twickler DM. Ultrasound predictors of placental invasion: the Placenta Accreta Index. 2014.
21. Silver RM, Landon MB, Rouse DJ, Leveno KJ, Spong CY, Thom EA, et al. Maternal morbidity associated with multiple repeat cesarean deliveries. Obstet Gynecol. 2006;107(6):1226-325.

Cite this article as: Samosir SM, Irianti S, Tjahyadi D. Diagnostic tests of placenta accreta index score (PAIS) as supporting prenatal diagnosis and outcomes of neonatal in abnormally invasive placenta management at general hospital of Hasan Sadikin Bandung. Int J Reprod Contracept Obstet Gynecol 2017;6:3765-9. 